DOI: 10.22559/folklor.1004

folklor/edebiyat, cilt: 25, sayı: 100, 2019/4

\title{
Atasözlerinde Eleştirel Düşünme Unsurlarr: Türkçe Ders Kitapları
}

\section{Critical Thinking Elements in Proverbs: Turkish Textbooks}

\author{
Zekerya Batur \\ Mehmet Soyuçok**
}

Öz

Bu çalışmada aynı zamanda bir öğretim materyali olan atasözlerinde bulunan eleştirel düşünme unsurları incelenmiştir. Çalışma betimsel olup tarama modelinde yapılmış ve veriler doküman incelemesi yoluyla toplanmıştır. Araştırmaya Milli Eğitim Bakanlığı tarafından yayınlanan Türkçe ders kitaplarındaki metin ve etkinliklerde bulunan bütün atasözleri dâhil edilmiştir. Atasözleri öncelikle araştırmacılar tarafından belirlenmiş, ardından da bulunan tüm atasözleri TDK çevrimiçi sözlüğünden (2018) kontrol edilmiştir. Son olarak da 3 alan uzmanının onayı alınmış ve liste netleştirilmiştir. Çalışmanın sonucunda, ders kitaplarındaki 44 fark11 atasözünün tamamında eleştirel düşünme unsurunun bulunduğu belirlenmiştir. Ancak Türkçede 18.838 atasözü olduğu göz önünde bulundurulduğunda kitaplardaki atasözü sayısının ne kadar az olduğu ortadadır. Yer verilen atasözü sayısının azlığının yanı sıra verilen atasözlerindeki eleştirel düşünce unsurları da zayıftır ve bu atasözleri, eleştirel düşünme basamaklarını yeterince temsil edememektedir. Özellikle 7 ve 8. sınıflardaki atasözlerinin eleştirel düşünme bakımından zayıflı̆̆ı, olumsuz bir durumdur. Hâlihazırdaki ortaokul Türkçe ders kitaplarındaki atasözleri, eleştirel düşünceyi günlük hayata taşımada ve pratik eleştirel düşünme becerisini geliştirmede öğrenciye bir katkı sağlamayacaktır. Ortaokul Türkçe ders kitap-

* Doç.Dr., Uşak Üniversitesi Eğitim Fakültesi, zekeryabatur@usak.edu.tr. ORCID: 0000-0002-7918-5305.

** Doktora öğrencisi, Uşak üniversitesi Sosyal Bilimler Enstitüsü. mehmetsoyucok@gmail.com. ORCID: 00000001-8388-2130. 
larında atasözlerine hem metinlerde hem de etkinliklerde daha fazla yer verilmeli ve bu atasözleri eleştirel düşünme gibi üst düzey düşünme becerilerinden unsurlar taşımalıdır. Böylece kültür aktarımı, örtük öğretme ve ana dili sevgisi kazandırma gibi işlevleri olan atasözlerinden daha verimli bir şekilde yararlanılabilecektir.

Anahtar sözcükler: atasözü, ders kitabı, eleştirel düşünme, unsur

\begin{abstract}
In this study, critical thinking elements in proverbs, which are also teaching materials, are examined. This qualitative study is done basing on document review. All proverbs included in the texts and activities of the Turkish textbooks published by the Ministry of National Education were included in the study. Proverbs were first determined by the researchers, and then all the proverbs were controlled from the TDK online dictionary (2018). Finally, the approval of 3 field experts was obtained and the list was clarified. As a result of the study, it was determined that there were critical thinking elements in 44 different proverbs in the textbooks. However, given that there are 18,838 proverbs in Turkish, the number of proverbs in books is clear. In addition to the limited number of proverbs, the critical thinking elements in the proverbs given are also weak and these proverbs do not adequately represent the critical thinking steps. The weakness of critical proverbs, especially in the 7 th and 8 th grades, is negative. The proverbs in the Turkish secondary textbooks in the current secondary school will not contribute to the students to develop critical thinking skills and to develop practical critical thinking skills. In secondary school Turkish textbooks proverbs should be given more in both texts and activities, and these proverbs should bear elements of high-level thinking skills such as critical thinking. Thus, proverbs with functions such as culture transfer, implicit teaching and love of native language can be used more efficiently.
\end{abstract}

Keywords: proverb, textbook, critical thinking, element.

\title{
Giriş
}

Atasözleri, bir dilin kültürüyle olan ilişkisini ortaya koyan en temel söz varlıklarından biri olarak görülmektedir (Alkayış, 2009, 289; Aydın, 2013, 175; Başgöz, 2008: 86; Christensen, 1958İ: 232; Duman, 2012: 226; Duman, 2009: 48; Jiang: 2000: 328; Karakuş ve Keçe, 2012: 133; Kim, 2003: 1; McKenna, 1974: 377; Sherzer, 1987: 295). Atasözü, etkili ve yoğun bir anlatıma sahip, söyleyeni bilinmeyen, bir mesaj verme kaygısı içinde olan özlü söz olarak tanımlanabilir. Atasözleri, halk bilgeliğinin dile gelmiş, somutlaşmış halidir (Mieder, 2004: 1). Bu yüzden de özellikle moral değerlerin öğretiminde sıklıkla başvurulan öğretim materyalleridir (Yankah, 1999: 205). Bu temel söz varlığı, yoruma dayalı, karmaşık ve ilgi çekici (Honeck, 2013: 1) olmakla birlikte toplum tarafından sıklıkla kullanılır (McKenna, 1974: 377). Teşekkül etme zamanları tam olarak bilinmeyen atasözlerinin dillerin yazıya geçirilmelerinden önce oluşmaya başladığı düşünülebilir (Dell, 2006, 2018; Obiechina, 1993: 123).

Atasözleri, metnin bağlamını derinden etkilediği için, bir metni okuyan kişi metindeki atasözlerine hâkim değilse okuduğunu tam olarak anlayamayacaktır (Katz ve Ferretti, 2003: 19). Ait olduğu dilin öğrenilmesinin kolay veya zor oluşu hakkında da fikir veren atasözlerini (Xinwei, 2006: 20) anlayabilmek için dilin ait olduğu kültüre hâkimiyetin yanı sıra iyi bir düşünme 
ve yargılama becerisine de sahip olmak gerekir (Gibbs ve Beitel, 1995: 133). Zihin performans1 ile atasözlerinin anlaşılması arasında doğrudan bir ilişki vardır (Uukerman, Thoma ve Daum, 2008: 51). Ayrıca atasözlerinin yoğun anlatımı ve toplum üzerindeki olumlu etkisi reklamcılık gibi sektörlerin de atasözleriyle ilgilenmesi sonucunu doğurmuştur (Qing-fang, 2004: 3). Atasözlerinde toplumun yaşayış biçimi ve yaşama bakış açısını görmek mümkündür. Atasözleri vasıtasıyla toplumun kültürü, sosyal alışkanlıkları, siyasi hayatı, ekonomisi vs. hakkında bilgi sahibi olunabilir (Bond, 1935: 724; Christensen, 1958: 232; Grant ve Asimeng-Boahene, 2006: 17). Bu bağlamda atasözleri insanların bir problemle karşılaştığında problemi nasıl çözdüğü ve sorguladığı hakkında bilgi vermektedir. Dolayısıyla atasözlerinde düz anlatım ya da aktarma söz konusu değildir, bunun aksine olay, olgu ya da durumlara eleştirel bakış vardır.

Eleştirel düşünme, karşılaşılan olay, olgu veya görüş üzerinde analiz, sentez, değerlendirme gibi üst düzey düşünme becerilerini kullanarak belirli kıstaslar yardımıyla sonuca ulaşmayı amaçlayan, tarafsız ve sistemli bir faaliyet gerektiren düşünme stilidir (Lai, 2011: 27; Scriven ve Paul, 2007: 98). Eleştirel düşünme, içinde bulunduğumuz bilgi ve bilişim çağında anahtar bir beceri konumuna gelmiştir (Adeyemi, 2012: 155; Astleitner, 2002: 53; Facione, 2015: 27; Gant, ve Smith, 2018; Martin, 2018: 1; Saputri, Sajidan, Rinanto, Afandi ve Prasetyanti, 2019: 327; Schultz, 2019: 201). Eleştirel düşünme becerisi için etkili, gerçek hayata dönük ve anlamlı etkinlikler uygulanmalıdır (Miri ve David, 2007: 353). Eleştirel düşünme süreci, bir nevi nitelikli sorular sorma ve değerlendirme yapma sürecidir. Bu sürecin tam olarak gerçekleşebilmesi için şu soruları sormak ve bunları cevaplamak gerekmektedir (Facione, 2004: 8):

\begin{tabular}{|l|l|}
\hline \multirow{3}{*}{ YORUMLAMA } & $\begin{array}{l}\text { - Söylenenler ne anlama geliyor? } \\
\text { - Ne oluyor? } \\
\text { • Bunu nasıl anlamalıyız? } \\
\text { - Bunu karakterize etmenin / sinıflandırmanın en iyi yolu nedir? } \\
\text { - Bu bağlamda, bunu söyleyerek / yaparak neyi amaçlamıştı? } \\
\text { - Bundan (deneyim, duygu veya ifade) nasıl anlam çıkarabiliriz? }\end{array}$ \\
\hline \multirow{5}{*}{ ANALİ } & $\begin{array}{l}\text { - Lütfen bu iddianın kabulü için nedenlerinizi tekrar belirtin. } \\
\text { - Sizin sonucunuz nedir / Ne iddia ediyorsunuz? } \\
\text { - Neden öyle düşünüyorsun? } \\
\text { - Destekleyici argümanlar nelerdir? } \\
\text {-Bu sonucu kabul etmek için hangi varsayımları yapmak } \\
\text { zorundayız? } \\
\text { - Bunu söylemenin temeli nedir? }\end{array}$ \\
\hline
\end{tabular}




\begin{tabular}{|c|c|}
\hline SONUÇ & $\begin{array}{l}\text { - Şu ana kadar bildiğimiz kadarıyla, hangi sonuçları çizebiliriz? } \\
\text { - Şimdiye kadar bildiğimiz şeyi göz önünde bulundurarak, neyi } \\
\text { dişlayabiliriz? } \\
\text { • Bu kanıt ne anlama geliyor? } \\
\text { • Bu varsayımı reddedersek / kabul edersek, işler nasıl değişirdi? } \\
\text { • Bu soruyu çözmek için hangi ek bilgilere ihtiyacımız var? } \\
\text { • Eğer bu şeylere inanırsak, ilerleyeceğimiz için neyi ima } \\
\text { ederlerdi? } \\
\text { • Bu şekilde şeyler yapmanın sonuçları nelerdir? } \\
\text { • Henüz keşfedilmemiş bazı alternatifler nelerdir? } \\
\text { - Her seçeneği göz önünde bulundurarak, bizi nereye } \\
\text { götüreceğini görelim. } \\
\text { •Öngörebileceğimiz ve öngörmemiz gereken herhangi bir } \\
\text { istenmeyen sonuç var mı? }\end{array}$ \\
\hline DEĞERLENDİRME & $\begin{array}{l}\text { - Bu iddia ne kadar güvenilirdir? } \\
\text { • Neden bu kişinin iddia ettiğine güvenebileceğimizi } \\
\text { düşünüyoruz? } \\
\text { • Bu argümanlar ne kadar güçlü? } \\
\text { • Gerçeklerimizi doğru mu algılıyoruz? } \\
\text { •Şimdi bildiklerimiz göz önüne alındığında sonucumuzdan ne } \\
\text { kadar emin olabiliriz? }\end{array}$ \\
\hline AÇIKLAMA & $\begin{array}{l}\text { - Soruşturmanın spesifik bulguları / sonuçları neydi? } \\
\text { - Lütfen bu analizi nasıl yaptığınızı bize bildirin. } \\
\text { - Bu yoruma nasıl geldiniz? } \\
\text { - Lütfen bizi bir kez daha düşünceni anlat. } \\
\text { - Neden böyle düşünüyorsunuz (doğru cevap / çözüm oldu)? } \\
\text { - Bu özel kararın neden verildiğini nasıl açıklarsınız? }\end{array}$ \\
\hline $\begin{array}{l}\text { KENDİNI } \\
\text { DÜZENLEME }\end{array}$ & $\begin{array}{l}\text { - Bu konudaki konumumuz hala çok belirsiz; daha kesin olabilir } \\
\text { miyiz? } \\
\text { - Metodolojimiz ne kadar iyi ve onu ne kadar iyi takip ettik? } \\
\text { - Bu çelişen iki sonucu uzlaştırabilmenin bir yolu var mı? } \\
\text { - Kanıtlarımız ne kadar iyi? } \\
\text { - Bazı tanımlarımızı biraz kafa karıştırıcı buluyorum; kesin } \\
\text { olarak ne demek istediğimizi tekrar gözden geçirebilir miyiz? }\end{array}$ \\
\hline
\end{tabular}

$\mathrm{Bu}$ soruları sorabilen ve cevaplayabilen bir öğrenci büyük ölçüde eleştirel düşünme yeterliliğine sahip demektir. Elbette her durumda bu sorular sorulmayacak, basit durumlarda pratiklerden faydalanılacaktır. Eleştirel düşünme, kişiler için toplum hayatına tam ve etkili olarak katılmada olmazsa olmaz bir unsurdur (Macknight, 2000: 38; Ten Dam ve Volman, 2004: 359). 21. yüzyıldaki hızlı iletişim ve bilgi akışı eleştirel düşüncenin önemini daha 
da arttırmaktadır (McPeck, 2016: 1). Eleştirel düşünce, eğitim öğretim konusunda da büyük öneme sahiptir. Kendi öğrenme deneyimlerine ve karşılaştığı kavramlara eleştirel gözle yaklaşamayan öğrenci, bilgi ve beceriyi özümseyemeyecek ve tam olarak öğrenemeyecektir (Paul ve Elder, 2005: 10).

Atasözleri bir milletin asırlar boyu edindiği deneyimleri ifade eden ve yeni nesillere yol gösteren veciz ifadelerdir. Bu veciz ifadeler, neyin, nasıl ve niçin yapılması gerektiğini etkili ve yoğun bir anlatımla ifade eder. Atasözleri yoluyla verilmek istenen bir mesaj rahatlıkla aktarılabilir (Arewa ve Dundes, 1964: 70). Atasözlerindeki ana fikirler, toplumun neye önem verdiğini, olay, olgu ve durumları nasıl kavrayıp anlamlandırdığını gösterir. Atasözlerine bakarak o toplumun düşünme şekilleri hakkında birçok ipucu elde edilebilir (Mieder, 2010: 54). Eleştirel düşünme ise her devirde hem toplumsal hem de bireysel açıdan önem taşıyan bir beceri olmakla birlikte önemini bilgi çağında iyice arttırmıştır. Bu bakımdan atasözlerinde eleştirel düşünceye ilişkin unsurların bulunma durumu, incelenmesi gereken bir konudur. $\mathrm{Bu}$ noktadan hareketle araştırma sürecinde aşağıdaki alt problemlere cevap aranacaktır:

1. Ortaokul 5. sınıf Türkçe ders kitaplarında yer alan atasözlerinde eleştirel düşünme unsurları yer almakta midır?

2. Ortaokul 6. sınıf Türkçe ders kitaplarında yer alan atasözlerinde eleştirel düşünme unsurları yer almakta midır?

3. Ortaokul 7. sınıf Türkçe ders kitaplarında yer alan atasözlerinde eleştirel düşünme unsurları yer almakta midir?

4. Ortaokul 8. sınıf Türkçe ders kitaplarında yer alan atasözlerinde eleştirel düşünme unsurları yer almakta midır?

\section{Yöntem}

Nitel olan bu çalışma doküman incelemesine dayanarak yapılmıştır. “Araştırma kapsamında incelenen konuyla ilgili olgu ve olaylar hakkında bilgi içeren yazılı belgelerin analiz edilmesiyle veri sağlanmasına doküman incelemesi denilmektedir” (Karataş, 2015: 72). Verilerin analizinde ise içerik analizi yapılmıştır. "İçerik analizi, nitel veri analiz türleri arasında en sık kullanılan yöntemlerden biridir. İçerik analizi ağırlıklı olarak yazılı ve görsel verilerin analiz edilmesinde kullanılan bir yöntemdir. Bu yöntemde tümdengelimci bir yol takip edilmektedir. İçerik analizinde araştırmacı öncelikli olarak araştırma konusu ile ilgili kategoriler geliştirmektedir. Araştırmacı daha sonra, incelemiş olduğu veri setinde, bu kategoriler içerisine giren kelime, cümle ya da resimleri saymaktadır" (Özdemir, 2010: 335).

Çalışmaya veri sağlanırken 2018-2019 eğitim öğretim yılında kullanılan ve Milli Eğitim Bakanlığı tarafından yayınlanan ortaokul Türkçe ders kitaplarından yararlanılmıştır. Araştırmaya ders kitaplarındaki metin ve etkinliklerde bulunan bütün atasözleri dâhil edilmiştir. Atasözleri öncelikle araştırmacılar tarafından belirlenmiş, ardından da bulunan tüm atasözleri TDK çevrimiçi sözlüğünden (2018) kontrol edilmiştir. Son olarak da 3 alan uzmanının onayı alınmış ve liste netleştirilmiştir. Atasözleri belirlendikten sonra her atasözü Facione (2004: 8) tarafindan ortaya konan eleştirel düşünme basamakları doğrultusunda incelenmiştir. Bu inceleme yapılırken önce eleştirel düşünme unsuru bulunup bulunmadığına bakılmış 
ardından eğer eleştirel düşünme unsuru varsa hangi basamak veya basamaklarda olduğu belirlenmiştir. İki aşamada da 3 alan uzmanından görüş ve onay alınmıştır.

\section{Bulgu ve yorumlar}

$\mathrm{Bu}$ bölümde araştırmanın alt problemlerine ilişkin bulgu ve yorumlara yer verilecektir. Elde edilen bulgular, alt problem başlıkları altında tablolar halinde verilmiş ve yorum yapılmıştır.

\subsection{Birinci Alt Probleme Yönelik Bulgu ve Yorumlar}

\begin{tabular}{|c|c|c|}
\hline ATASÖZÜ & $\begin{array}{l}\text { ELEŞTİREL } \\
\text { DÜŞÜNME } \\
\text { UNSURU }\end{array}$ & $\begin{array}{l}\text { ELEŞTIREL } \\
\text { DÜŞÜNME } \\
\text { BASAMAĞI }\end{array}$ \\
\hline Bakarsan bağ olur, bakmazsan dağ olur. & Var & $\begin{array}{l}\text { Yorumlama, Analiz, } \\
\text { Sonuç, Değerlendirme, } \\
\text { Açılama }\end{array}$ \\
\hline Birlikten kuvvet doğar. & Var & $\begin{array}{l}\text { Sonuç, Değerlendirme, } \\
\text { Açıklama }\end{array}$ \\
\hline İşleyen demir pas tutmaz. & Var & $\begin{array}{l}\text { Sonuç, Değerlendirme, } \\
\text { Açıllama }\end{array}$ \\
\hline Her yiğidin bir yoğurt yiyişi vardır. & Var & $\begin{array}{l}\text { Sonuç, Değerlendirme, } \\
\text { Açılama }\end{array}$ \\
\hline Gülü seven dikenine katlanır. & Var & $\begin{array}{l}\text { Sonuç, Değerlendirme, } \\
\text { Açılama }\end{array}$ \\
\hline Dağ dağa kavuşmaz, insan insana kavuşur. & Var & $\begin{array}{l}\text { Sonuç, Değerlendirme, } \\
\text { Açılama }\end{array}$ \\
\hline Ayağını yorganına göre uzat. & Var & $\begin{array}{l}\text { Değerlendirme, } \\
\text { Kendini düzenleme }\end{array}$ \\
\hline Sürüden ayrilan kuzuyu kurt kapar. & Var & $\begin{array}{l}\text { Değerlendirme, } \\
\text { Kendini düzenleme }\end{array}$ \\
\hline Ağaç yaş iken eğilir. & Var & $\begin{array}{l}\text { Sonuç, Değerlendirme, } \\
\text { Açılama }\end{array}$ \\
\hline Kabahat samur kürk olsa kimse sırtına almaz. & Var & $\begin{array}{l}\text { Sonuç, Değerlendirme, } \\
\text { Açılama }\end{array}$ \\
\hline Ne ekersen onu biçersin. & Var & $\begin{array}{l}\text { Analiz, Değerlendirme, } \\
\text { Açıklama }\end{array}$ \\
\hline Taşıma su ile değirmen dönmez. & Var & $\begin{array}{l}\text { Analiz, Değerlendirme, } \\
\text { Açılama }\end{array}$ \\
\hline Keski sirke küpüne zarardır. & Var & $\begin{array}{l}\text { Değerlendirme, } \\
\text { Kendini düzenleme }\end{array}$ \\
\hline Üzüm üzüme baka baka kararır. & Var & $\begin{array}{l}\text { Analiz, Sonuç, } \\
\text { Değerlendirme, } \\
\text { Açıklama }\end{array}$ \\
\hline
\end{tabular}




\begin{tabular}{|l|l|l|}
\hline Bülbülün çektiği dilinden... & Var & Açıklama \\
\hline Çok sözünü az söyle, az sözünü öz söyle. & Var & $\begin{array}{l}\text { Sonuç, Değerlendirme, } \\
\text { Açıklama }\end{array}$ \\
\hline $\begin{array}{l}\text { Danışan dağları aşmış, danışmayan düz yolda } \\
\text { şaşmış. }\end{array}$ & Var & $\begin{array}{l}\text { Sonuç, Değerlendirme, } \\
\text { Açıklama }\end{array}$ \\
\hline Duvara dayanma yıkılır, insana güvenme ölür. & Var & $\begin{array}{l}\text { Yorumlama, Sonuç, } \\
\text { Değerlendirme }\end{array}$ \\
\hline Baş başa vermeyince taş yerinden kalkmaz. & Var & $\begin{array}{l}\text { Sonuç, Değerlendirme, } \\
\text { Açılama }\end{array}$ \\
\hline
\end{tabular}

5. sınıf Türkçe ders kitaplarında 19 atasözü bulunduğu, bunların hepsinde eleştirel düşünme unsurlarının yer aldığı ve eleştirel düşünme basamaklarının tamamının temsil edildiği görülmektedir. Bilişsel düzeyler açısından 5. sınıf öğrencileri somut işlemler dönemini yaşamaktadırlar (Piaget, 2007: 140). Dolayısıyla bu döneme yönelik ders kitaplarına alınacak kelime, kavram ve atasözlerinin de bu döneme uygun olması beklenmektedir. Tablo incelendiğinde kitaptaki atasözlerinin büyük oranda mecaz anlamlı seviye açısından uygun olmadığ̣ görülmektedir. Atasözlerinde her ne kadar eleştirel düşünme becerilerine yer verilmiş olmasına öğrencilerin seviyesine uygun olmaması atasözlerinin amaca uygun kullanılmasını güçleştirmektedir.

\section{2. İkinci alt probleme yönelik bulgu ve yorumlar}

\begin{tabular}{|c|c|c|}
\hline ATASÖZÜ & $\begin{array}{c}\text { ELEŞTİREL } \\
\text { DÜŞÜNME } \\
\text { UNSURU } \\
\end{array}$ & $\begin{array}{l}\text { ELEŞTİREL } \\
\text { DÜŞÜNME } \\
\text { BASAMAĞI } \\
\end{array}$ \\
\hline Birlikten kuvvet doğar. & Var & Sonuç \\
\hline Yalancının mumu yatsıya kadar yanar. & Var & $\begin{array}{l}\text { Yorumlama, Analiz, } \\
\text { Sonuç, Değerlendirme, } \\
\text { Açıklama }\end{array}$ \\
\hline Lafla peynir gemisi yürümez. & Var & $\begin{array}{l}\text { Analiz, Sonuç, } \\
\text { Değerlendirme, Açıklama }\end{array}$ \\
\hline Borç yiğidin kamçısıdır. & Var & Değerlendirme, Açıklama \\
\hline Davulun sesi uzaktan hoş gelir. & Var & $\begin{array}{l}\text { Analiz, Sonuç, } \\
\text { Değerlendirme, Açıklama }\end{array}$ \\
\hline Komşu komşunun külüne muhtaçtır. & Var & $\begin{array}{l}\text { Sonuç, Değerlendirme, } \\
\text { Açıklama }\end{array}$ \\
\hline Ay ışığında ceviz silkilmez. & Var & $\begin{array}{l}\text { Sonuç, Değerlendirme, } \\
\text { Açıklama }\end{array}$ \\
\hline Keskin sirke küpüne zarar. & Var & $\begin{array}{l}\text { Değerlendirme, Kendini } \\
\text { düzenleme }\end{array}$ \\
\hline İşleyen demir pas tutmaz. & Var & Değerlendirme, Açıklama \\
\hline Acı patlıcanı kırağı çalmaz. & Var & Değerlendirme, Açıklama \\
\hline
\end{tabular}




\begin{tabular}{|l|l|l|}
\hline Aç tavuk kendini buğday ambarında sanır. & Var & $\begin{array}{l}\text { Değerlendirme, Kendini } \\
\text { düzenleme }\end{array}$ \\
\hline Ak akçe kara gün içindir. & Var & Değerlendirme, Açılama \\
\hline Meyve veren ağaç taşlanır. & Var & $\begin{array}{l}\text { Analiz, Değerlendirme, } \\
\text { Sonuç }\end{array}$ \\
\hline Ağacı kurt, insanı dert yer. & Var & $\begin{array}{l}\text { Açılama, Analiz, } \\
\text { Değerlendirme, Sonuç }\end{array}$ \\
\hline Ağaç yaşken eğilir. & Var & Açılama, Değerlendirme \\
\hline Ağaç yaprağıyla gürler. & Var & $\begin{array}{l}\text { Açılama, } \\
\text { Değerlendirme, Sonuç }\end{array}$ \\
\hline
\end{tabular}

Ortaokul 6. sınıf Türkçe ders kitabı incelendiğinde 16 atasözü bulunduğu görülmektedir. Bu atasözlerinden 3'ünün 5. sınıf kitabında da yer aldığı ve bütün eleştirel düşünme basamaklarının temsil edildiği belirlenmiştir. 6. sınıf öğrencileri de 5. sınıf öğrencileri gibi genel olarak somut işlemler dönemindedirler (Piaget, 2007: 120). Dolayısıyla bu öğrenciler somut kelime, kavram ya da atasözlerini daha kolaylıkla kavrayabilmektedir. Ancak tablodaki atasözleri incelendiğinde öğrencilerin bulunduğu bilişsel seviyenin dikkate alınmadığı söylenebilir. Bununla beraber ortaokul 6. sınıf Türkçe ders kitaplarındaki atasözlerinde eleştirel düşünme unsurlarına yer verildiği; bu atasözlerinden 3 tanesinin ise 5. sınıf ders kitabında da yer aldığ 1 ve atasözlerinde bütün eleştirel düşünme basamaklarının temsil edildiği belirlenmiştir.

\section{3. Üçüncü alt probleme yönelik bulgu ve yorumlar}

\begin{tabular}{|l|l|l|}
\hline \multicolumn{1}{|c|}{ ATASÖzÜ } & $\begin{array}{c}\text { ELEŞTIREL } \\
\text { DÜŞÜNME } \\
\text { UNSURU }\end{array}$ & $\begin{array}{l}\text { ELEŞTIREL DÜŞÜNME } \\
\text { BASAMAĞI }\end{array}$ \\
\hline Bir fincan kahvenin kırk yıl hatırı vardır. & Var & Açıklama, Değerlendirme \\
\hline $\begin{array}{l}\text { Gönül ne kahve ister ne kahvehane, } \\
\text { gönül sohbet ister kahve bahane. }\end{array}$ & Var & Açıklama, Değerlendirme \\
\hline Can boğazdan gelir. & Var & Açıklama, Değerlendirme \\
\hline Rüzgar eken fırtına biçer. & Var & $\begin{array}{l}\text { Analiz, Açıklama, } \\
\text { Değerlendirme }\end{array}$ \\
\hline El elden üstündür & Var & $\begin{array}{l}\text { Sonuç, Analiz, Açıklama, } \\
\text { Değerlendirme }\end{array}$ \\
\hline Damlaya damlaya göl olur. & Var & $\begin{array}{l}\text { Yorumlama, Sonuç, Analiz, } \\
\text { Açıklama, Değerlendirme }\end{array}$ \\
\hline
\end{tabular}

Ortaokul 7. sınıf Türkçe ders kitabında 6 atasözü yer almakta ve eleştirel düşünme basamaklarının tamamı temsil edilmektedir. 7. sınıf öğrencileri 5 ve 6 . sınıf öğrencilerine göre bilişsel beceriler açısından daha farklı düşünebilmekte ve mecaz ifadeleri daha rahat anlayabilmektedirler (Tay, Kurnaz ve Taşdemir, 2010: 243). 7. sınıf ders kitabındaki atasözü sayısı 5 ve 6. sınıf ders kitaplarındaki atasözü sayısına göre daha az ve seviyeye daha uygun oldukları görülmektedir. Bu da atasözlerinin seçiminde seviye ve sıklık açısından herhangi bir kural ya da ölçüt bulunmadığını ortaya koymaktadır. 
2.4. Dördüncü alt probleme yönelik bulgu ve yorumlar

\begin{tabular}{|l|l|l|}
\hline \multicolumn{1}{|c|}{ ATASÖzÜ } & $\begin{array}{c}\text { ELEŞTIREL } \\
\text { DÜŞÜNME } \\
\text { UNSURU }\end{array}$ & \multicolumn{1}{|c|}{$\begin{array}{c}\text { ELEŞTIREL DÜŞÜNME } \\
\text { BASAMAĞI }\end{array}$} \\
\hline Yiğit başından devlet ırak değildir. & Var & $\begin{array}{l}\text { Yorumlama, Analiz, Açıklama, } \\
\text { Değerlendirme }\end{array}$ \\
\hline Yiğit yarasına yiğit katlanır. & Var & Açılama, Değerlendirme \\
\hline Koç yiğit bunalıp ölmez. & Var & $\begin{array}{l}\text { Yorumlama, Analiz, Açılama, } \\
\text { Değerlendirme }\end{array}$ \\
\hline Yiğit yiğide at bağışlar. & Var & $\begin{array}{l}\text { Yorumlama, Açıklama, } \\
\text { Değerlendirme }\end{array}$ \\
\hline İş insanın aynasıdır. & Var & $\begin{array}{l}\text { Analiz, Sonuç, Yorumlama, } \\
\text { Açılama, Değerlendirme }\end{array}$ \\
\hline Yalnız taş duvar olmaz. & Var & $\begin{array}{l}\text { Sonuç, Yorumlama, Açıklama, } \\
\text { Değerlendirme }\end{array}$ \\
\hline Davulun sesi uzaktan hoş gelir. & Var & $\begin{array}{l}\text { Analiz, Sonuç, Yorumlama, } \\
\text { Açılama, Değerlendirme }\end{array}$ \\
\hline
\end{tabular}

Ortaokul 8. sınıf Türkçe ders kitabında yer alan 8 atasözünün tamamında eleştirel düşünme unsure bulunmakta ve eleştirel düşünme basamaklarının tamamı temsil edilmektedir. 8. sınıf öğrencileri diğer sınıf seviyelerine göre sosyolojik, psikolojik, fizyolojik, fiziksel ve bilişsel olarak daha farklı bir dönem yaşamaktadırlar (Tay, Kurnaz ve Taşdemir, 2010). Bu dönemde öğrencilere sunulan her türdeki eğitim ve öğretim sunumlarının, öğrencilerin gelişim özelliklerine uygun olması gerekmektedir. 8. sınıf öğrencileri soyut düşünme becerilerini kazanmalarının yanı sıra bedensel olarak da büyük değişimler yaşamaktadırlar. Bu noktadan hareketle ders kitaplarına alınan atasözlerinin de bu dönemin özelliklerini yansıtmasının faydalı olabileceği söylenebilir. Diğer sınıf seviyelerine göre 8. sınıfta somut anlamlı atasözlerine daha fazla yer verildiği görülmektedir. Bu durumun, 5 ve 6. sinıf ders kitaplarında beklenirken 8 . sınıf ders kitabında görülmesi, atasözlerinin seçiminde herhangi bir ölçütün olmadığını göstermektedir. Ancak kitaptaki atasözlerine eleştirel düşünme unsurları açısından bakıldığında zengin olduğu söylenebilir.

\section{Sonuç ve tartışma}

Atasözleri yoluyla binlerce kelime ile anlatılabilecek durumlar, sadece bir cümleyle anlatılabilmektedir. Bu nedenle okuma metinlerinde ve etkinliklerde atasözlerine yer vermek örtük kültür öğretiminin yanı sıra, öğrencinin ana dilinin en özlü ve veciz ifadelerini görmesini, zamanla da günlük konuşmasında kullanmasını sağlayacaktır. Bu yolla öğrencinin ifade becerisi geliştirilecek ve kültür aktarımı sağlanacaktır. Ortaokul Türkçe ders kitaplarına bakıldığındaysa atasözlerinin bu işlev ve yararlarının göz önünde bulundurulmadığı anlaşılmaktadir. 
Çalışmanın sonucunda, ders kitaplarındaki 44 farklı atasözünün tamamında eleştirel düşünme unsurunun bulunduğu belirlenmiştir. Türkçede 18.838 atasözü olduğu (Albayrak, 2009) göz önünde bulundurulduğunda kitaplardaki atasözü sayısının oldukça az olduğu görülmektedir. Yer verilen atasözü sayısının azlığının yanı sıra verilen atasözlerindeki eleştirel düşünce unsurları da zayıftır ve bu atasözleri, eleştirel düşünme basamaklarını yeterince temsil edememektedir. Atasözleri genelde bir cümleyle birçok duygu, düşünce ve durumu anlatma özelliğine sahiptir. Yani genellikle üst düzey ve çok yönlü düşünme becerisi gerektirir. Atasözlerinin kitaplardaki dağılımına bakıldığında ise bu duruma uygun olmayan bir şekilde sınıf seviyesi yükseldikçe atasözü sayısının azaldığı görülmektedir.

Bulgular incelendiğinde Türkçe ders kitaplarındaki atasözü sayısı az da olsa eleştirel düşünme unsurlarını taşıyan atasözlerinin yer aldığı görülmektedir. Demir (2006) tarafından yapılan çalışmada 5. sınıf öğrencilerinin eleştirel düşünme becerilerinin yüksek olduğu belirtilmiştir. Bu bakımdan her sınıf seviyesinde daha fazla sayıda atasözünden etkili bir şekilde faydalanmak mümkün iken bunun yapılmadığı söylenebilir. Özellikle 7 ve 8 . sınıflardaki atasözlerinin eleştirel düşünme bakımından zayıflığı, olumsuz bir durum olarak düşünülmektedir. Çünkü eleştirel düşünme, ortaokuldaki her sınıfta yer verilmesi gereken bir beceridir, eleştirel düşünme becerileri sınıf seviyesine göre bir farklılık göstermezken (Özmutlu, Kaymak, Gürler ve Demir, 2014) Türkçe ders kitaplarındaki eleştirel düşünme unsuru taşıyan atasözleri sayısı sınıf bazında büyük farklılıklar göstermektedir. Eleştirel düşünme unsuru taŞıyan atasözlerinin dağılımı literatürdeki bulgularla da çelişmektedir. Örneğin 7. sınıf Türkçe ders kitabında diğer sınıflara göre daha az atasözü yer almakta; Dolayısıyla daha az eleştirel düşünme unsuru yer almaktadır. Bunun yanında yapılan çalışmalarda 7. sınıf öğrencilerinin orta seviyede eleştirel düşünme yapabildikleri ortaya konmuştur (Demir ve Kan, 2017). Bu bağlamda bu sınıf seviyesinde öğrencilerin eleştirel düşünme becerilerinin çeşitli etkinliklerle geliştirilebileceği sonucuna ulaşılabilir.

Hâlihazırdaki ortaokul Türkçe ders kitaplarındaki atasözleri, eleştirel düşünmeyi günlük hayata taşımada ve pratik eleştirel düşünme becerisini geliştirmede öğrenciye bir katkı sağlamayacağı düşünülmektedir. Hâlbuki eleştirel düşünme becerilerinin geliştirilme zorunluluğu açıktır, Ersoy ve Başer (2011) tarafından yapılan çalışmada ortaokuldaki bütün sınıf seviyelerinde öğrencilerin eleştirel düşünme becerilerinin düşük olduğu ortaya konulmuştur. $\mathrm{Bu}$ noktadan hareketle ortaokul Türkçe ders kitaplarında atasözlerine hem metinlerde hem de etkinliklerde daha yer fazla verilmesi ve bu atasözlerinin eleştirel düşünme gibi üst düzey düşünme becerilerini edindirmede olabildiğince faydalanılması gerektiği söylenebilir. Böylece kültür aktarımı, örtük öğretme ve ana dili sevgisi kazandırma gibi işlevleri olan atasözlerinden daha verimli bir şekilde yararlanılabilecektir. Bu bağlamda atasözleri artık sadece kompozisyon ya da düşünce yazıları yazmak için kullanılmamalıdır. Çünkü atasözlerinde eleştirel düşünme unsurlarının tamamının yer aldığı net bir şekilde ortaya çıkmıştır. Öğrencilere eleştirel düşünme becerisi kazandırılırken atasözlerinden yararlanılarak verilmesi halinde, hem dil öğretimi hem de kültür öğretimi gerçekleşmiş olacaktır. Bununla birlikte 21. yüzyılın temel becerileri arasında yer alan eleştirel düşünme ve problem çözme becerilerinin geliştirilmesi son derece önemsenmektedir. Bundan dolayı da atasözleri ayrı bir önem taşımaktadır. Çünkü atasözleri sosyal yaşamın izlerini ve birikimini taşımaktadır. Sonuç olarak bu 
beceriler verilirken kültürel kodlardan yararlanılarak eğitim ve öğretim gerçekleştirilmelidir. Kültürel kodları temsil eden unsurların başında da atasözleri gelmektedir. Dolayısıyla kültür aktarmanın yanında özellikle düşünme becerilerinin kazandırılmasında da etkin bir şekilde yararlanılabilir. Çünkü atasözlerinde eleştirel düşünme becerilerinin tüm aşamalarının etkin bir şekilde yer aldığı görülmektedir. Dolayısıyla atasözleri her sınıfa göre seviyelendirilerek Türkçe ve Sosyal Bilgiler dersi öğretim programlarının kazanımları arasında yer almalıdır.

\section{Kaynaklar}

Adeyemi, S. B. (2012). Developing critical thinking skills in students: A mandate for higher education in Nigeria. European Journal of Educational Research. S.1, ss. 155-161.

Albayrak, N. (2009). Türkiye Türkçesinde atasözleri. İstanbul: Kap1.

Alkayış, M. F. (2009). Dini içerikli atasözleri üzerine. e-Sosyal Bilimler Dergisi. S. 8(27), ss. 287-292.

Astleitner, H. (2002). Teaching critical thinking online. Journal of instructional psychology. No. 29(2),pp. 53-76.

Arewa, E. O. and Dundes, A. (1964). Proverbs and the ethnography of speaking folklore 1. American Anthropologist. No. 66 (6 Part 2), pp. 70-85.

Aydın, S. (2013). Kültürel bir miras olarak atasözlerinin kullanımı üzerine Türkçe öğretmenlerinin görüşleri. folklor/edebiyat. S. 19 (75), ss. 173-192.

Baş, B. (2002). Türkçe temel dil becerilerinin öğretiminde atasözlerinin kullanımı. Pamukkale Üniversitesi Eğitim Fakültesi Dergisi, S. 2 (12), ss. 60-68.

Başgöz, İ. (2008). Atasözleri hakkında atasözleri ya da atasözlerinin toplumsal anlamı. Millî Folklor. S. 8 (70), ss. 85-91.

Batur, Z. (2011). Atasözü ve deyimlerde kadın ve kadının sosyo-psikolojik özellikleri. Turkish StudiesInternational Periodical for the Languages, Literature and History of Turkish or Turkic-, 6 (3), ss. 577-584.

Batur, Z. ve Erkek, G. (2017). İlk ve ortaokul Türkçe kitapları: Atasözleri. International Journal of Language Academy. S. 5 (4), ss. 19-32.

Batur, Z. ve Yavaşça, H. (2018). Dinle atasözünü oyna öğren özünü: Atasözü öğretimi. ADEDER, S. 3 (2), ss. 93-117.

Bekiroğlu, (2014). Türkçe atasözlerinde iletişim olgusunun izleri ve sosyo-kültürel çıkarımları. Millî Folklor. 26 S.103, ss. 80-97.

Bond, D. F. (1935). The law and lawyers in English proverbs. American Bar Association Journal. V. 21 (11), pp. 724-727.

Bulut, M. (2013). Türkçe eğitimi ve öğretiminde dil ve kültür aktarımı aracı olarak atasözleri ve deyimlerin önemi. Turkish Studies. S. 8 (13), ss.559-575.

Christensen, J. B. (1958). The role of proverbs in fanteculture. Africa. V. 28 ( 3),pp. 232-243.

Çinemre, S. (2014). Türk atasözlerindeki dini ve ahlaki motiflerin eğitim-öğretim ortamında kullanılması. Değerler Ĕgitimi Dergisi. S. 12(27), ss. 99-122.

Christensen, C. B. (1958). The role of proverbs in fante culture. Africa: Journal of the International African Institute. V. 28 (3), pp. 232-243.

Dell, K. J. (2006). The book of proverbs in social and theological context. Cambridge: Cambridge University. 
Demir, M. K. (2006). İlköğretim dördüncü ve beşinci sınıf öğrencilerinin sosyal bilgiler derslerinde eleştirel düşünme düzeylerinin çeşitli değişkenler açısından incelenmesi. Gazi Üniversitesi Gazi Eğitim Fakültesi Dergisi. S. 26 (3), ss. 155-169.

Demir, R. and Kan, M. O. (2017). 7. Sınıf öğrencilerinin eleştirel okuma becerileri. Mersin University Journal of the Faculty of Education. S. 13 (2), ss. 666-682.

Duman, M. (2009). Sözlü kültür ürünlerimizde giyim motifi. Türk Kültürü ve Hacı Bektaşi Veli. S.49, ss. $225-235$.

Duman, M. (2012). Türk atasözlerinde “ölüm”. Prof. Dr. Fikret Türkmen Armağanı, İzmir: Ege Üniversitesi.

Ersoy, E., Başer, N. (2009). İlköğretim ikinci kademede eleştirel düşünmenin yeri. Adnan Menderes Üniversitesi Ĕ̆itim Fakültesi Dergisi. S. 2(1),ss. 1-10.

Facione, P. A. (1998). Critical thinking: What it is andwhy it counts. Retrieved June, Measured Reasons LLC, Hermosa Beach, CA.

Facione, (2015). Critical thinking: What it is and why it counts. Measured Reasons LLC, Hermosa Beach, CA.

Gant, M. and Smith, M. (2018).Quantifying assessment of undergraduate critical thinking. Journal of College Teaching \& Learning. S. 15(1), ss. 27-38.

Gibbs, R. W. and Beitel, D. (1995). What proverb understanding reveal sabout how people think. Psychological Bulletin, S. 118 (1), ss. 133.

Gürel, E. ve Tat, M. (2012). Bir iletişim edimi olarak dinleme ve Türkçede bulunan dinleme temalı atasözleri ile deyimler üzerine bir içerik analizi. Uluslararası Sosyal Araştırmalar Dergisi. ss. 276297.

Honeck, R. P. (2013). A proverb in mind: The cognitive science of proverbial lwitand wisdom. Londra: Psychology.

Jiang, W. (2000). The relationship between culture and language. ELT Journal, S. 54 (4), ss. 328-334.

Karakuş, U. ve Keçe, M. (2012). Türk atasözlerinde doğal çevre algısı ve çevre eğitimi açısından önemi. ZfWT. S. 4 (3), ss. 131-145.

Karataş, Z. (2015). Sosyal bilimlerde nitel araştırma yöntemleri. Manevi Temelli Sosyal Hizmet Araştırmaları Dergisi. S. 1(1), ss. 62-80.

Katz, A. N., and Ferretti, T. R. (2003). Reading proverbs in context: The role of explicit markers. Discourse Processes. S. 36 (1), ss. 19-46.

Kim, L. S. (2003). Exploring the relationship between language, culture and identity. GEMA Online Journal of Language Studies. No. 3(2), pp.1-13.

Lai, E. R. (2011). Critical thinking: A literature review. Financial Times Group and the Penguin Group.

Martin, E. M. (2018).Teaching critical-thinking skills: A strategic-management class project. Journal of Instructional Pedagogies, V.21, pp.1-12.

McKenna, J. F. (1974). Theproverb in humanisticstudies: language, literature and culture; the oryand classroom practice. The French Review. V. 48(2), pp. 377-391.

MacKnight, C. B. (2000). Teaching critical thinking through online discussions. Educause Quarterly, S. 23 (4), ss. 38-41.

McPeck, J. E. (2016). Critical thinking and education. Routledge.

Mieder, W. (2004). Proverbs: A handbook. Greenwood Publishing Group. 
Mieder, W. (2010). American proverbs: An international, national, and global phenomenon. Western Folklore. Ss. 35-54.

Mieder, W. (2007). The proof of the proverb is in the probing. Folklore, 7-52.

Miri, B., David, B. C., and Uri, Z. (2007). Purposely teaching for the promotion of higher-order thinking skills: A case of critical thinking. Research in Science Education, 37 (4), 353-369.

Obiechina, E. (1993). Narrative proverbs in the African novel. Research in African Literatures, 24(4), 123-140.

Qing-fang, X. I. E. (2004). The innovative use of proverbs in advertising. English [J]. Journal of Pla University of Foreign Languages, S.5, ss.3.

Onan, B. (2011). Türk atasözlerinde dil farkındalığı ve işlevsel dil kullanımı. Millî Folklor, S. 23 (9), ss. 191-100.

Özdemir, M. (2010). Nitel veri analizi: Sosyal bilimlerde yöntembilim sorunsalı üzerine bir çalışma. Eskişehir Osmangazi Üniversitesi Sosyal Bilimler Dergisi, S. 11 (1), ss. 323-343.

Özmutlu, P., Gürler, I., Kaymak, H., ve Demir, ö. (2014). Ortaokul öğrencilerinin eleştirel okuma becerilerinin çeşitli değişkenlere göre incelenmesi. Electronic Turkish Studies, S.9, ss.3.

Ulutaş, M. ve Batur, Z. (2018). Sayıların atasözü ve deyimlere yükledikleri anlamlar. International Journal of Languages' Education and Teaching, 6 (3), 361-377.

Paul, R., and Elder, L. (2005). Critical thinking competency standards. Tomales, CA: Foundation for Critical Thinking.

Piaget, J. (2007). Çocukta dil ve zihin gelişimi. (S. E. Siyavuşgil, Çev.), Ankara: Palme.

Saputri, A. C., Sajidan, Rinanto, Y., Afandi, ve Prasetyanti, N. M. (2019). Improving students' critical thinking skills in cell-metabolism learning using stimulating higher order thinking skills model. International Journal of Instruction, V. 12 (1), pp. 327-342.

Schultz, B. E. (2019). How critical is critical thinking? Defense AT\&L.

Shahiditabar, M. ve Setayesh, K. (2015). A content-based analysis of humanity in Azerbaijani proverbs. International Journal of Innovation and Research in Educational Sciences, V. 2( 5),pp. 425-427.

Sherzer, J. (1987).A discourse-centered approach to language and culture, American Anthropologist. No. 89( 2),pp. 295-309.

Tay, B., Kurnaz, Ş. ve Taşdemir, M. (2010). The development of causality concept of primary school students in the instruction of social studies. Elementary Education Online, No. 9(1), pp. 241-255.

Tekşan, K. (2012). Atasözlerinin dil bilgisi öğretiminde kullanılabilirliği. Türk Bilimi Araştırmaları Dergisi, S. XXXI, ss. 301-322.

Ten Dam, G. and Volman, M. (2004). Critical thinking as a citizenshipcompetence: Teaching strategies. Learning andinstruction, No. 14(4), pp. 359-379.

Türkmen, S. (2009). Atasözleri ve deyimlerde yaşayan kişi adları. Dil Araştırmaları Dergisi, S.4, ss.101-119.

Uekermann, J. Thoma, P., and Daum, I. (2008). Proverb interpretation changes in aging. Brain and Cognition, V. 67(1), pp. 51-57.

Xin-wei, X. I. E. (2006). An analysis of Chinese proverbteaching in second language teaching [J]. Language and Translation, No. 4, pp. 0-20.

Yankah, K. (1999). Atasözü. Dilbilim Antropolojisi Dergisi, S. 9 (1-2), ss. 205-207.

Yılmaz, M. (2000). Türkçe atasözlerinde eğitim anlayışı. A.Ü. Eğitim Bilimleri Fakültesi Dergisi, S.33, ss.137-145. 


\section{Elektronik kaynaklar}

Türk Dil Kurumu (TDK). (2018). Atasözü ve deyimler çevrim içi sözlüğü. http://www.tdk.gov.tr/index. php?option=com_atasozleri\&view=atasozleri $(08 / 11 / 2018$ tarihinde erişildi.) 